\title{
Effect of Vanadium Addition on the Strength of API X100 Linepipe Steel
}

\author{
Shahrooz NAFISI, ${ }^{1) *}$ Babak Shalchi AMIRKHIZ, ${ }^{2)}$ Fateh FAZELI, ${ }^{2)}$ Muhammad ARAFIN ${ }^{3)}$ Robert GLODOWSKI ${ }^{4)}$ \\ and Laurie COLLINS ${ }^{1)}$
}

1) EVRAZ INC. NA, P.O. Box 1670, Regina, SK, S4P 3C7 Canada.

2) CanmetMATERIALS, Natural Resources Canada, Hamilton, ON, L8P OA5 Canada. $\quad 3)$ CanmetMATERIALS, Natural Resources Canada, Calgary AB, T2L 2A7 Canada. $\quad 4)$ EVRAZ Stratcor Inc., 200 East Randolph Drive, Suite 7800, Chicago, IL, 60601 USA.

(Received on June 18, 2015; accepted on October 6, 2015)

\begin{abstract}
Laboratory heats of high strength low alloy steels with yield strength of $100 \mathrm{ksi}$ (API X100) were produced with and without vanadium addition. Upon mechanical testing of the rolled plates, it was determined that 0.06 wt. $\% \mathrm{~V}$ increased the yield and tensile strengths from 8 to $14 \%$ in all directions without adverse effects on toughness or ductility. Transmission Electron Microscopy (TEM) was used to study the distribution and structure and volume density of precipitation in the two steels. A higher number density of smaller carbonitride precipitates with more uniform distribution was observed in the V-added alloy compared to the steel without vanadium. Size and volume density of the carbonitride precipitates were measured based on EDX elemental maps of $\mathrm{Nb}, \mathrm{V}$ and Ti, and measuring thickness of the TEM samples. It is shown that the volume density of carbonitride precipitates in the V-added sample is one order of magnitude higher than the base alloy. Ashby-Orowan analysis indicated that the additional precipitation density due to vanadium addition made partial contribution to the observed increase in strength. Other possible strengthening mechanisms caused by carbonitride precipitates such as their effect on dislocation recovery in bainite and refinement of bainite microstructure are also discussed.
\end{abstract}

KEY WORDS: API X100; linepipe; EBSD; TEM; EELS; niobium; vanadium.

\section{Introduction}

Vanadium microalloying of linepipe steels has been used traditionally for producing API X50 through X70 strength levels, ${ }^{1)}$ using the precipitation strengthening component of $\mathrm{V}$ along with the austenite conditioning properties of $\mathrm{Nb}$ and/or Ti. The result was a primarily ferritic microstructure with an excellent combination of strength and toughness. As the requirements for strength increased to X80 and higher, the microstructure required to develop these properties moved to lower transformation products, acicular ferrite and bainite. With the lower finish cooling temperatures required to achieve these microstructures, the potential benefit of $\mathrm{V}$ precipitation strengthening was considered to diminish due to inadequate opportunity for $\mathrm{V}(\mathrm{C}, \mathrm{N})$ to precipitate. ${ }^{2-4)}$ However, other beneficial strengthening effects of vanadium addition could be exploited in bainitic strips and linepipe steels. 5,6$)$

Siwecki et al., ${ }^{5)}$ in their study of bainitic hot strip steel, suggested that retardation/prevention of the dislocation

\footnotetext{
Part of the work was done by employees of the Government of Canada, who prepared the work in connection with their official duties. As such, the work is Crown Copyright and is NOT assigned to the ISIJ. The undersigned acknowledges, however, that the ISIJ has the right to publish, distribute and reprint the work in all forms and media.

* Corresponding author: E-mail: Shahrooz.Nafisi@evrazna.com DOI: http://dx.doi.org/10.2355/isijinternational.ISIJINT-2015-290
}

recovery might be the most dominant mechanism of the strength gain, while precipitation strengthening could still play a role but only to a lesser extent. However, previous studies from the authors ${ }^{6)}$ indicated that the additional strength in the V-containing X100 linepipe steel might have originated from a combination of several factors such as precipitation and solid solution strengthening, smaller grains as well as prevention of dislocation recovery in bainite. While precipitation was identified as an important strengthening mechanism, the formation of sufficient number of uniformly distributed ultra-small carbonitride precipitates containing $\mathrm{V}$ which could provide sufficiently high strengthening effect was not fully evident.

In this study, advanced material characterization techniques were used with transmission electron microscopy (TEM) to qualitatively/quantitatively study and compare the strengthening contribution from precipitates in both steels. New findings may better identify the underlying strengthening mechanisms for enhanced properties of the $\mathrm{V}$-added linepipe steel.

\section{Experimental Procedure}

API X100 steel was made by hot rolling of a $127 \mathrm{~mm}$ thick cast ingot to $14 \mathrm{~mm}$ final gauge. The steel contained (wt.\%) $0.06 \% \mathrm{C}, 1.95 \% \mathrm{Mn}, 0.41 \% \mathrm{Mo}, 0.16 \% \mathrm{Cr}, 0.03 \% \mathrm{Nb}$, $0.005 \mathrm{Ti}, 0.0055 \% \mathrm{~N}$, and two levels of $\mathrm{V}$, i.e. a residual 
level of $0.004 \% \mathrm{~V}$ and an addition of $0.063 \% \mathrm{~V}$ (alloys $\mathrm{A}$ and $\mathrm{B}$ respectively).

The cast ingots were reheated at $1180^{\circ} \mathrm{C}$ for $2.5 \mathrm{hrs}$ and then rolled to $14 \mathrm{~mm}$ final gauge. ${ }^{6,7)}$ An overall grain refinement was expected by rough rolling $64 \%$ in 7 passes above the calculated non recrystallization temperature, i.e. $\mathrm{T}_{\mathrm{nr}}\left(958^{\circ} \mathrm{C}\right)^{8)}$ to achieve adequate recrystallization of the ascast austenite grains. Finish rolling was a $72 \%$ cumulative reduction in 6 passes in the austenite region below $\mathrm{T}_{\mathrm{nr}}$. The rough rolling was started at about $1125^{\circ} \mathrm{C}$ and finished at about $1010^{\circ} \mathrm{C}$. Finish rolling started at $880^{\circ} \mathrm{C}$ and finished at about $792^{\circ} \mathrm{C}$. The rolled steels were then accelerated cooled to about $450^{\circ} \mathrm{C}$ at $30^{\circ} \mathrm{C} / \mathrm{s}$, then slowly cooled at $15^{\circ} \mathrm{C} / \mathrm{hr}$ for 24 hours. $\operatorname{Ar} 3$ and $\operatorname{Ar} 1$ temperatures were measured by Gleeble simulation non-deformed under cooling rate of $2^{\circ} \mathrm{C} /$ min and values were measured as $759^{\circ} \mathrm{C}$ and $647^{\circ} \mathrm{C}$ for alloy $\mathrm{B}$ and $756^{\circ} \mathrm{C}$ and $637^{\circ} \mathrm{C}$ for alloy $\mathrm{A}$, respectively.

Samples for mechanical testing were cut at different angles from the rolling direction. For optical microscopy and TEM works, samples were cut from quarter thickness with a precision saw using a general purpose diamond wafering blade. For TEM sample preparation a FEI Helios NanoLab $650 \mathrm{~S}$ dual beam system was used to prepare cross sectional samples using gallium as the source through liftout technique. The small size of FIB samples minimized the effect of magnetism of the sample on the electron beam

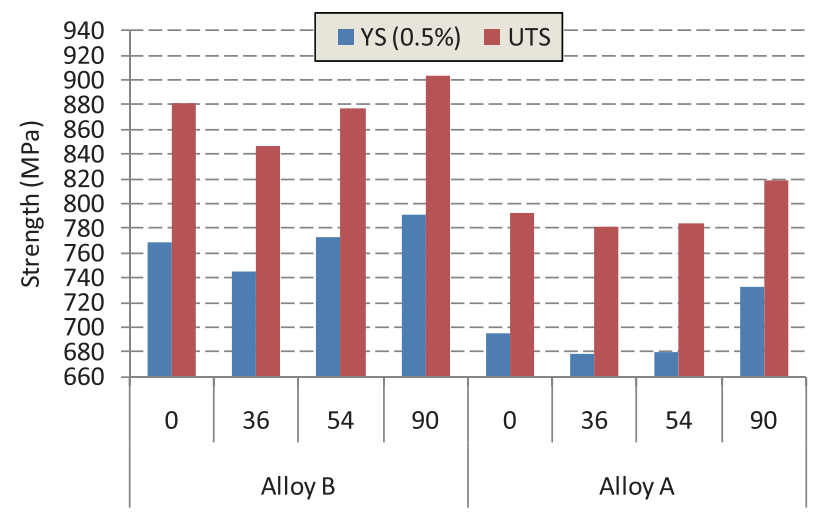

Fig. 1. Yield and Tensile strengths ( $\mathrm{X}$ axis shows angles to the rolling direction). (Online version in color.)(reproduced from Ref.6).

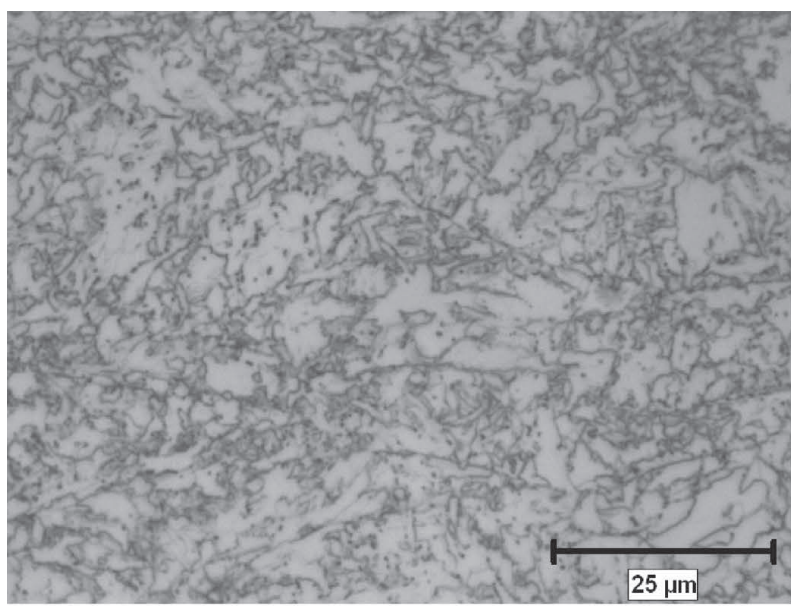

Alloy A allowed for higher quality imaging needed for characterization of nanometric precipitates. FEI Tecnai Osiris TEM operating at $200 \mathrm{kV}$ with conventional bright field-dark field imaging, along with Scanning Transmission Electron Microscopy (STEM) mode using the high angle annular dark field (HAADF) detector, combined with Energy Dispersive X-ray Spectroscopy (EDX) were used to study the microstructure and directly image the precipitates through elemental mapping. In order to measure the volume density of the carbonitride precipitates, thickness measurement was done based on EELS (Electron Energy Loss Spectroscopy) log-ratio technique. ${ }^{9)}$

\section{Results and Discussion}

The addition of $0.06 \% \mathrm{~V}$ resulted in an increase of both yield and tensile strengths of 60 to $95 \mathrm{MPa}$ in all tested directions (Fig. 1). Charpy toughness and elongation results were nearly identical for the steels with and without vanadium addition. The microstructure of both the base and vanadium microalloyed material contained mostly bainitic ferrite with small amounts of quasi polygonal ferrite and MA constituents (Fig. 2). Texture analysis indicated very similar results, with some slight indications of more desirable components in the vanadium added steel, i.e. $\{332\}<113>$ and $\{554\}<225>$. EBSD analyses indicated the presence of higher fraction of low angle boundaries as well as lower grain size in the vanadium steel than the base material, details could be found elsewhere. ${ }^{\text {) }}$

The general microstructural features of alloys A and B are shown by STEM-HAADF images in Fig. 3. A STEM probe size of approximately $1 \mathrm{~nm}$ was used for imaging and EDX mapping. It appears that the alloy containing $\mathrm{V}$ has a finer microstructure with smaller bainitic laths whereas in the baseline sample equiaxed ferrite grains are the dominant features. Bainite packets containing aggregate of parallel laths were occasionally seen in V-added specimens but were not obvious in samples with no V. The corresponding EDX elemental maps of $\mathrm{Nb}$ are also shown in Fig. 3 for both alloys as a representation of the extent of precipitation. It is quite clear that relatively smaller and a higher number density of precipitates was seen in the case of the

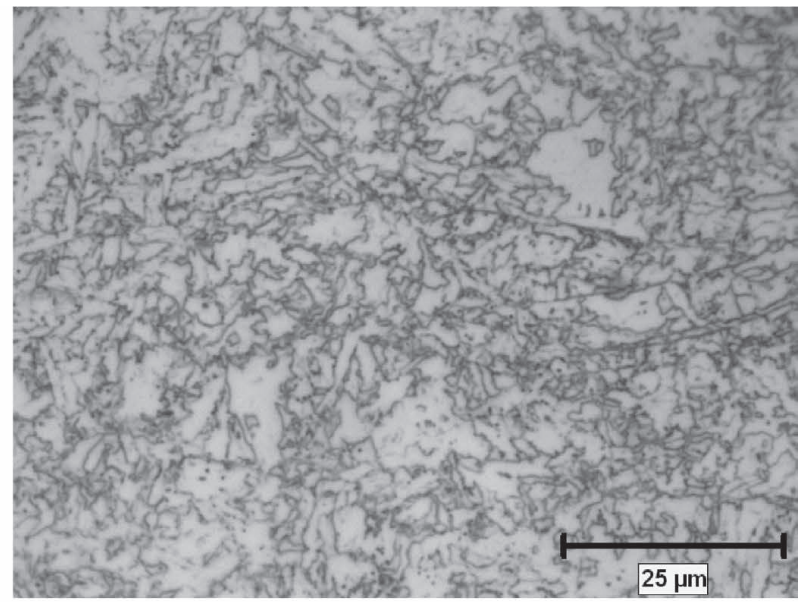

Alloy B

Fig. 2. Typical optical micrographs at quarter thickness. 

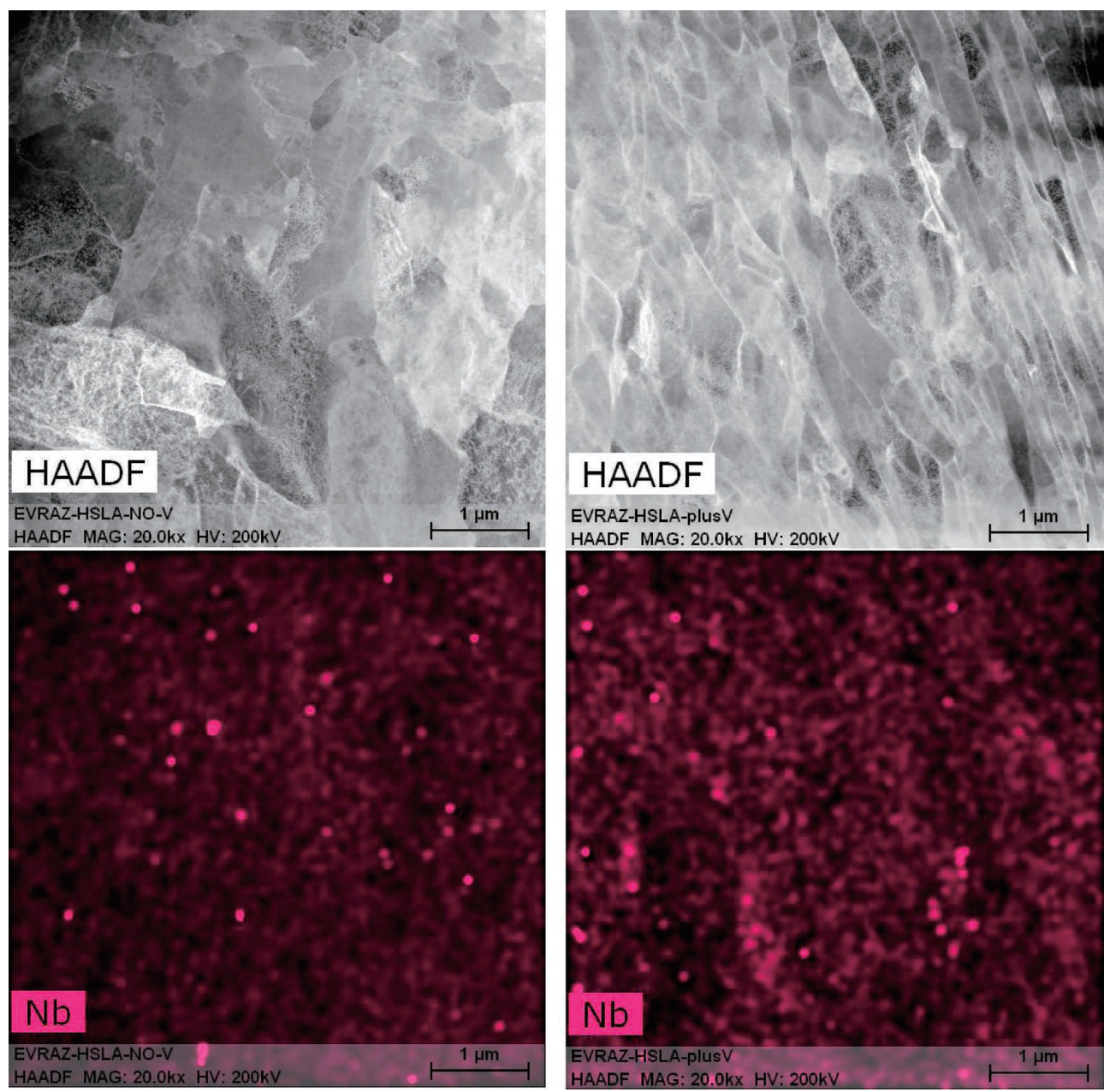

Fig. 3. STEM-HAADF images showing general microstructure of alloy A and alloy B and their corresponding Nb elemental maps representing $\operatorname{NbTi}(\mathrm{CN})$ in alloy A and $\operatorname{NbTiV}(\mathrm{CN})$ in alloy B. Note that a filter is used on the $\mathrm{Nb}$ map of alloy A to enhance the signal over the background. (Online version in color.)
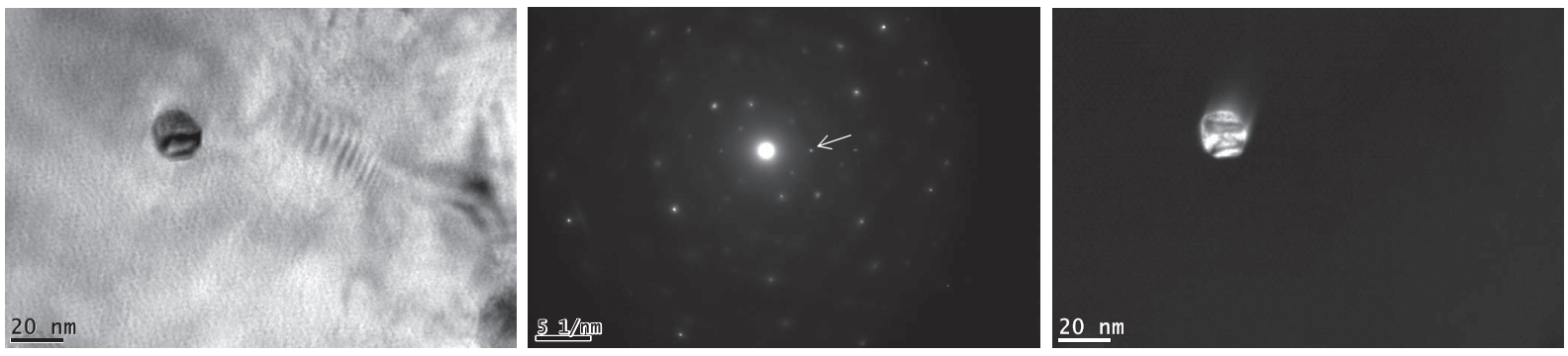

Fig. 4. TEM bright field and corresponding SAD of a region in the V-added alloy containing a (TiV)CN precipitate. The dark field is formed from the arrowed reflection which corresponds to (111) plane of (TiV)CN. Crystallographic information of the carbonitride is given in reference. ${ }^{19)}$

V-containing sample (alloy B). Diffraction analysis of the precipitates confirmed their $\mathrm{Ti}(\mathrm{CN})$ structure. One example is shown in Fig. 4 where the dark field image is taken using (111) reflection of the $\mathrm{Ti}(\mathrm{CN})$ carbide in Alloy B. It should be noted that $\mathrm{TiC}$, TiN, and $\mathrm{Ti}(\mathrm{CN})$ precipitates all have $\mathrm{F} \mathrm{m}$ $-3 \mathrm{~m}$ space group, and $\mathrm{V}$ or $\mathrm{Nb}$ could substitute Ti without changing the lattice structure.

In Fig. 5, a region of alloy $A$ is shown along with EDX elemental maps of $\mathrm{Ti}, \mathrm{Nb}, \mathrm{N}, \mathrm{V}$, and $\mathrm{C}$ which represent precipitation of $\mathrm{TiNb}(\mathrm{CN})$ in this alloy (note that in the carbon map, regions containing carbides show up as they have higher $\mathrm{C}$ content). In Fig. 6, a region of alloy $\mathrm{B}$ is shown which represent precipitation of $\operatorname{TiNbV}(\mathrm{CN})$ in this alloy. It is evident that most of the detected precipitates contain a large amount of vanadium. Such maps have been analyzed to measure volume density as well as the size of the carbonitride precipitates which will be presented later.

If steel is alloyed with two or more microalloying elements, complex precipitates may form in austenite, at the interface, and/or in ferrite. These precipitates may be found as a single phase solid solution such as $\operatorname{TiNb}(\mathrm{C}),{ }^{10)}$ or by nucleation on the pre-existing precipitates. Then, the new precipitates could be found either as a shell surrounding the precipitates (like $\mathrm{NbV}(\mathrm{CN})$ around $\mathrm{TiN}^{11)}$ ) or as a cap on the existing precipitate (like $\mathrm{Nb}(\mathrm{CN})$ nucleation on $\mathrm{TiN}^{12)}$ ). As shown in Fig. 7, $\mathrm{TiNb}(\mathrm{CN})$ precipitates in alloy A, usually 
ISIJ International, Vol. 56 (2016), No. 1

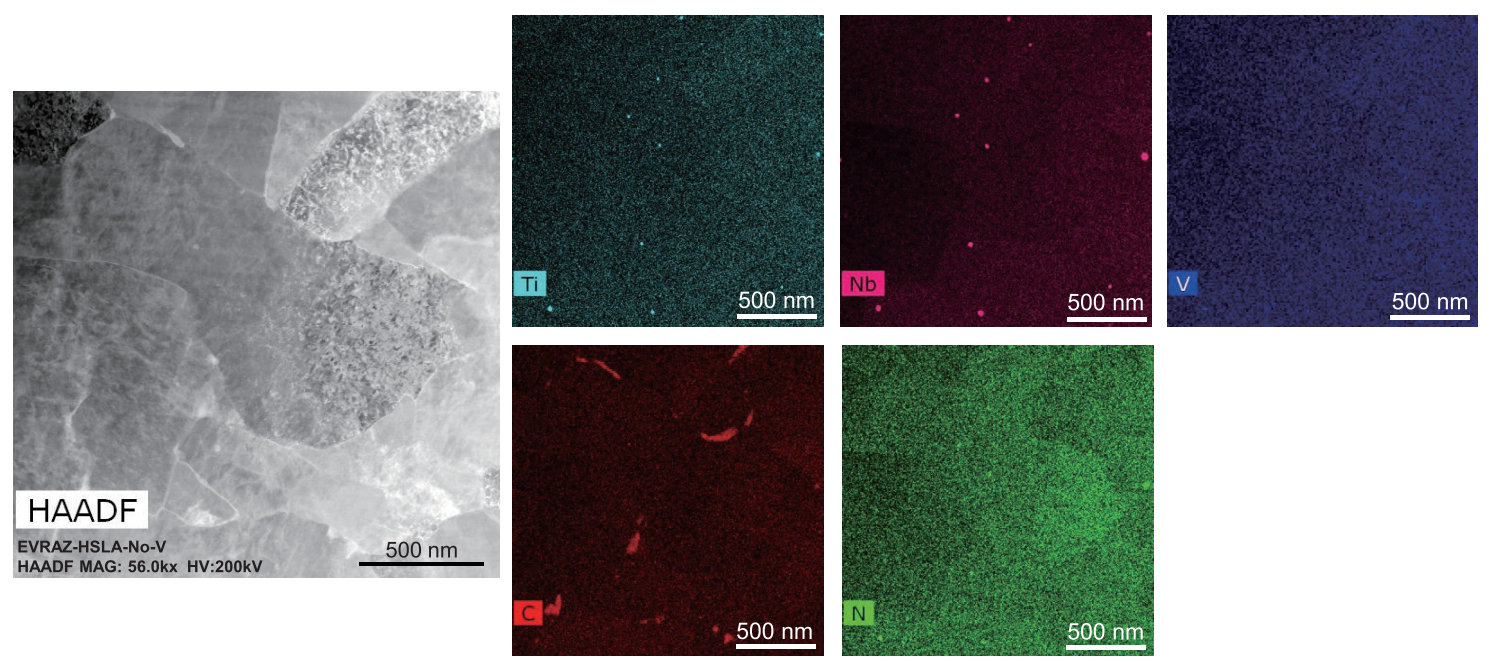

Fig. 5. TEM and EDS elemental maps for alloy A. Precipitation includes $\mathrm{TiNb}(\mathrm{CN})$ type. (Online version in color.)
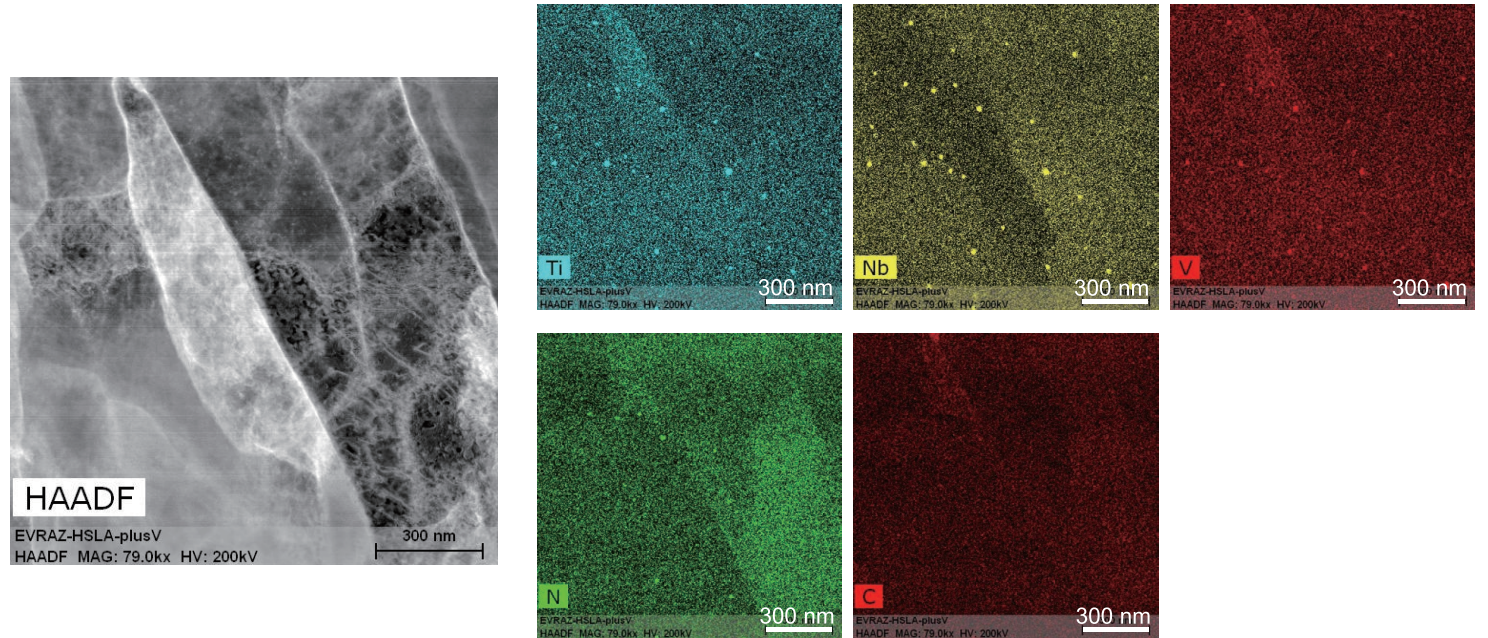

Fig. 6. TEM and EDS elemental maps for alloy B. Precipitation includes $\mathrm{VTiNb}(\mathrm{CN})$ type. (Online version in color.)
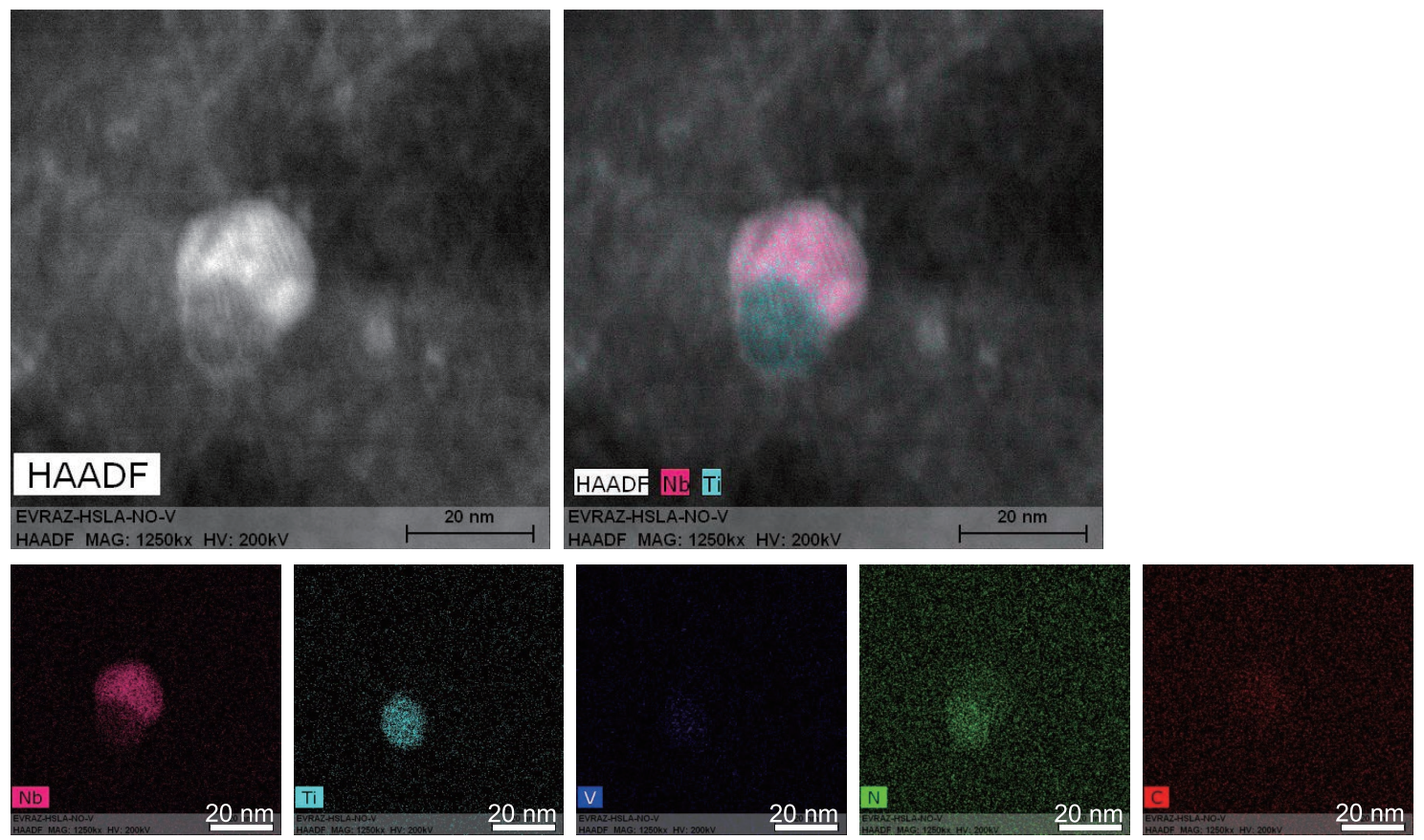

Fig. 7. STEM-HAADF image and corresponding EDS elemental maps from a $\mathrm{TiNb}(\mathrm{CN})$ precipitate in alloy A. The precipitate shows a core of $\mathrm{Ti}(\mathrm{CN})$ with a cap of $\mathrm{Nb}(\mathrm{CN})$. (Online version in color.) 

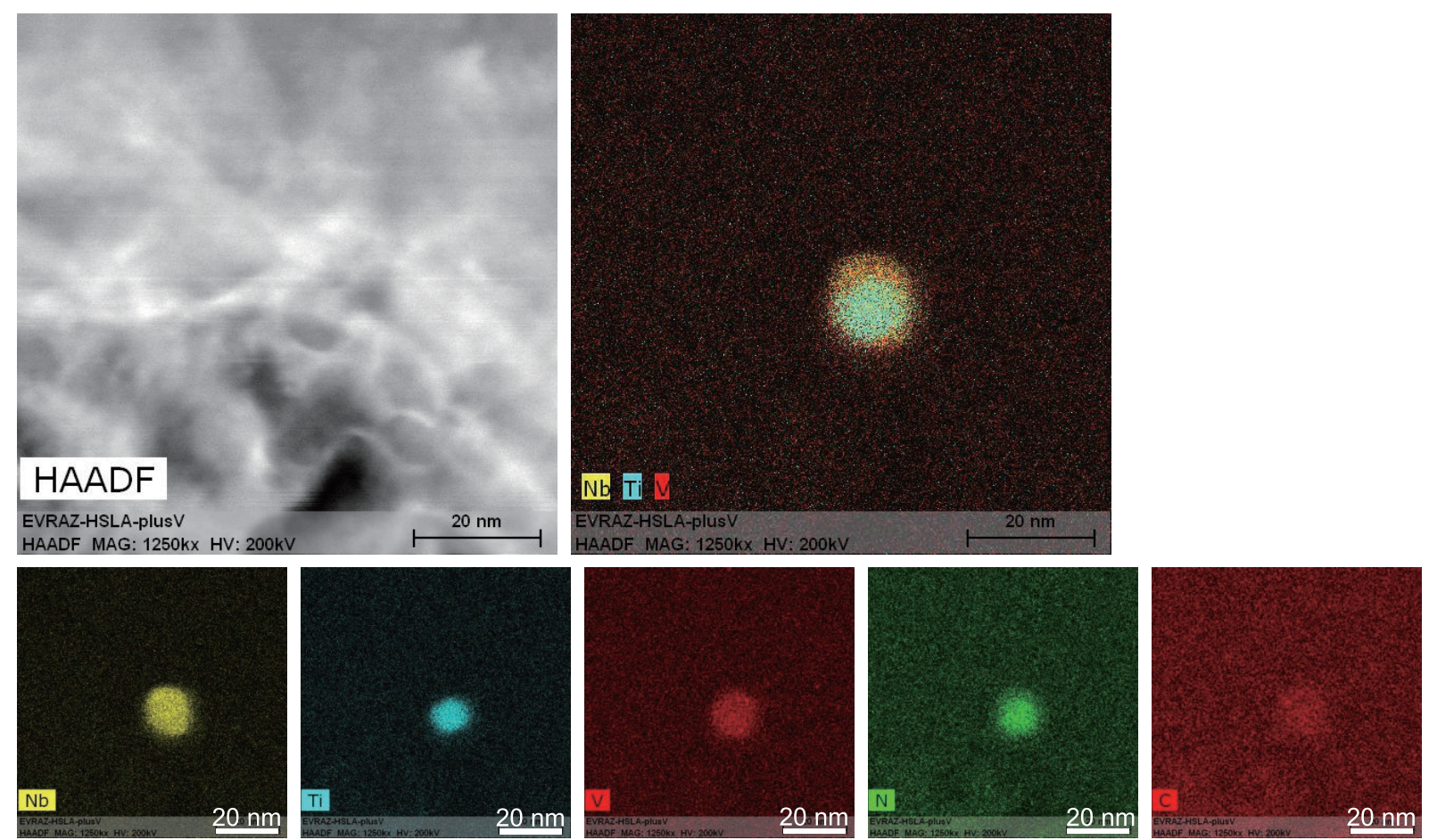

Fig. 8. STEM-HAADF image and corresponding EDS elemental maps from a TiNbV(CN) precipitate in Alloy B. The precipitate shows a core of $\mathrm{Ti}(\mathrm{CN})$ with a shell of $\mathrm{VNb}(\mathrm{CN})$. (Online version in color.)

consisted of a "core" of $\mathrm{Ti}(\mathrm{CN})$ and a "cap" of $\mathrm{Nb}(\mathrm{CN})$ with an average size of approximately $25 \mathrm{~nm}$. Whereas, in alloy B (Fig. 8), the carbonitride precipitates were made up of a core of $\operatorname{Ti}(\mathrm{CN})$ and a shell of $\mathrm{NbV}(\mathrm{CN})$ and had a smaller average size around $18 \mathrm{~nm}$. Nonetheless, in both samples, $\mathrm{Ti}(\mathrm{CN})$ particles predominantly act as nucleation site.

The number of precipitates was counted visually using V, $\mathrm{Ti}$, and $\mathrm{Nb}$ maps as well as the combination maps. Care was taken not to count a precipitate more than once. In the area where the number of the precipitates was counted, EELS (Electron Energy Loss Spectroscopy) log-ratio thickness measurement was also performed at several points to measure an average thickness of the examined foils which was used for calculating the volume density of the precipitates. The results of volume density measurements are given in Table 1.

Previous TEM work using extraction replicas showed that $\mathrm{V}$-containing steel had a higher volume of small precipitates $(<10 \mathrm{~nm})$ but it was unclear whether all precipitates were identified in the TEM carbon replica image and if their volume fraction is sufficient for effective precipitation strengthening to this extent. ${ }^{6}$ ) The current estimated volume fraction of microalloying carbonitride particles (Table 1) can be compared with the prediction of Thermo-Calc ${ }^{\mathrm{TM}}$. The evolution of equilibrium precipitates with temperature for $\mathrm{V}$-containing and V-free steels is illustrated in Fig. 9. Themo-Calc suggests that TiN starts forming around $1380^{\circ} \mathrm{C}$ which is below the solidus temperature and the composition evolves toward $(\mathrm{TiNb}) \mathrm{N}$ as the precipitation further continues. $\mathrm{Nb}(\mathrm{CN})$ forms in austenite below $1090^{\circ} \mathrm{C}$. The maximum combined volume fraction of $(\mathrm{TiNb}) \mathrm{N}$ and $\mathrm{Nb}(\mathrm{CN})$ is predicted to be about $4.4 \times 10^{-4}$ (at $700^{\circ} \mathrm{C}$ ). The equilibrium evolution of $\mathrm{Ti}$ and $\mathrm{Nb}$ based precipitates are not affected by vanadium addition as shown in Fig. 9(b); however below
Table 1. Measured volume fraction and calculated strengthening contribution of microalloying precipitates.

\begin{tabular}{ccccc}
\hline & $\begin{array}{c}\text { Average } \\
\text { size, nm }\end{array}$ & $\begin{array}{c}\text { Number } \\
\text { density, } \mathrm{cm}^{-3}\end{array}$ & $\begin{array}{c}\text { Volume } \\
\text { fraction }(f)\end{array}$ & $\begin{array}{c}\text { Strength, } \\
\mathrm{MPa}\end{array}$ \\
\hline $\begin{array}{c}\text { V-free } \\
\text { (Alloy A) }\end{array}$ & $25 \pm 6.9$ & $8.9 \times 10^{12}$ & $7.0 \times 10^{-5}$ & 14 \\
$\begin{array}{c}\text { V-added } \\
\text { (Alloy B) }\end{array}$ & $18 \pm 3.6$ & $9.0 \times 10^{13}$ & $2.8 \times 10^{-4}$ & 34 \\
\hline
\end{tabular}

about $930^{\circ} \mathrm{C}$ the formation of $(\mathrm{VNb}) \mathrm{N}$ is expected to occur. Subsequently below $800^{\circ} \mathrm{C}$ vanadium atoms precipitate mainly as VC. The volume fraction of $\mathrm{VC}$ precipitations rises abruptly as material cooled into ferrite region and approaches to its maximum fraction of $1 \times 10^{-3}$ (at $700^{\circ} \mathrm{C}$ ) due to low solubility of carbon in ferrite.

In the current study, during the processing of the examined steel the hot bands were cooled from finish rolling temperature (FRT) of $\sim 792^{\circ} \mathrm{C}$ rapidly to $450^{\circ} \mathrm{C}$. This fast cooling between $792^{\circ} \mathrm{C}$ and $450^{\circ} \mathrm{C}$, which coincides with the predicted temperature range of $\mathrm{VC}$ formation (dotted line in Fig. 9(b)), is unlikely to provide sufficient time for precipitation of vanadium. This is consistent with the current TEM finding indicating the lack of distinct VC. Literature data, ${ }^{e . g .13)}$ such as detailed SAXS (Small Angle X-ray Scattering) and SANS (Small Angle Neutron Scattering) analyses of a $0.4 \mathrm{C}-0.3 \mathrm{~V}(\mathrm{wt} \%)$ steel, also confirms that vanadium precipitation requires adequate time to reach equilibrium, e.g. $30 \mathrm{~min}$ at $700^{\circ} \mathrm{C}$; and the reaction becomes very sluggish below $600^{\circ} \mathrm{C}$. The size of vanadium carbide particles was found to decrease from $23 \mathrm{~nm}$ to $0.5 \mathrm{~nm}$ over 700 to $600^{\circ} \mathrm{C}$ temperature range and no traces of precipitation were observed at lower holding temperatures. ${ }^{13)}$ Similarly, the current TEM study did not reveal $0.5-1 \mathrm{~nm}$ 

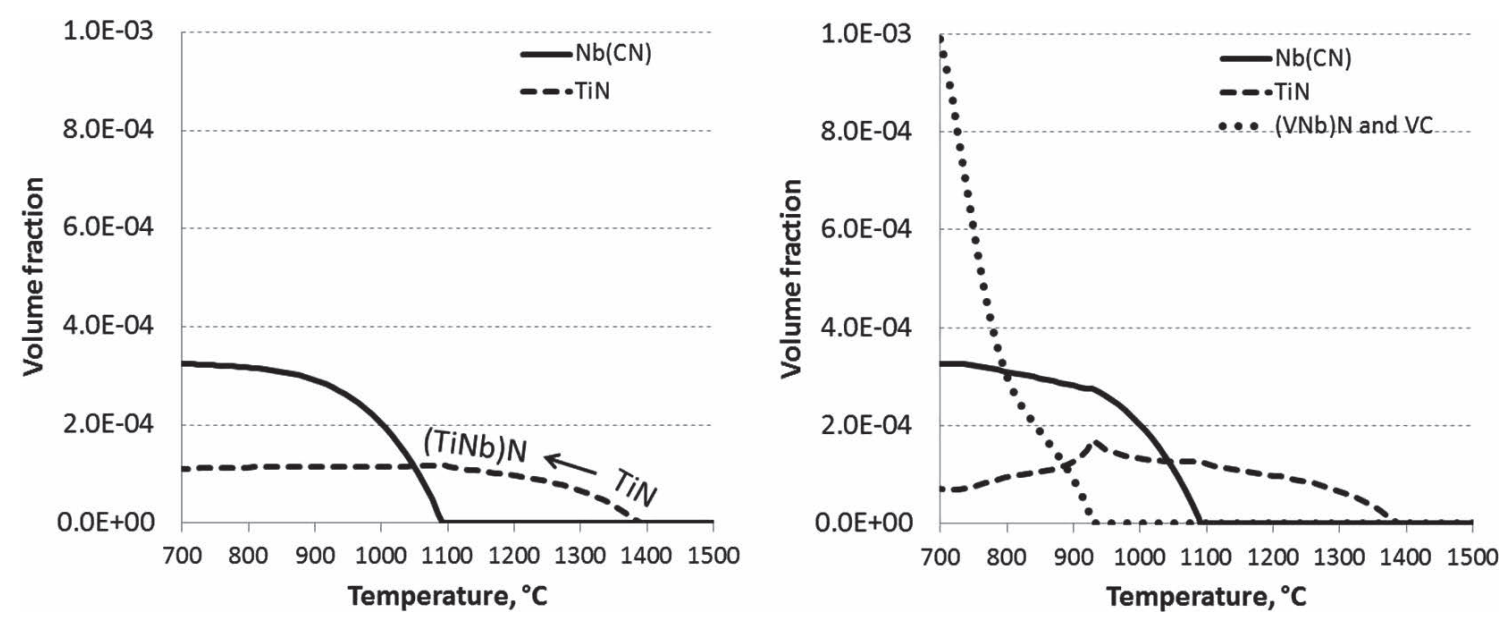

Fig. 9. The predicted volume fraction of microalloying precipitates at different temperatures for (a) V-free and (b) V-added steels.

size V-containing particles which would be a signature of precipitation at $450^{\circ} \mathrm{C}$ coiling temperature.

Nevertheless, the TEM results suggest that alloying with vanadium promoted a higher number density of $\mathrm{Ti}$ and $\mathrm{Nb}$ carbonitrides with $\sim 18 \mathrm{~nm}$ average diameter, which are finer compared to the observed precipitates of the base $\mathrm{V}$-free alloy, i.e. $25 \mathrm{~nm}$. The finer carbonitride particles, most likely formed during rough and finish rolling, not during the cooling and subsequent coiling stage. It has to be noted also that the combined volume fraction of $\operatorname{TiNbV}(\mathrm{CN})$ particles in alloy $\mathrm{B}$ is greater than the fraction of $\mathrm{TiNb}(\mathrm{CN})$ precipitates in alloy $\mathrm{A}$, as indicated by Table 1 .

A simple analysis can be carried out to estimate the strengthening effect of the aforementioned coarse and fine groups of precipitates. Both populations of $25 \mathrm{~nm}$ and 18 $\mathrm{nm}$ carbonitride precipitates in $\mathrm{V}$-free and $\mathrm{V}$-added alloys are non-shearable. As such the strengthening contribution is calculated using the Ashby-Orowan model which describes adequately the strengthening of precipitates between 3-30 nm sizes: ${ }^{14)}$

$$
\sigma=\alpha \frac{G b}{2 \pi L} \ln \beta \frac{r}{b}
$$

where, $\alpha$ and $\beta$ are constants, i.e 2.4 and 0.8 respectively, $G$ denotes the shear modulus; $80.3 \mathrm{GPa}, b$ is the magnitude of the Burger's vector; $2.5 \times 10^{-10} \mathrm{~m}, r$ is particle radius and $L$ represents interparticle spacing given by $L=r \sqrt{2 \pi / 3 f}$ ( $f$ is volume fraction). A normal size distribution of precipitates was observed for the two alloys, as such the average diameter and total volume fraction of carbonitride precipitates were used to estimate the ensuing precipitation contribution.

The calculation results for the strengthening effect of precipitates are included in Table 1. In the base alloy, the contribution of precipitates with average size of $25 \mathrm{~nm}$ to the overall strength is $\sim 14 \mathrm{MPa}$. Microalloying with vanadium gave rise to the formation of finer precipitates with higher number density and volume fraction. Additional strength was calculated due to this refinement of precipitation size and distribution. As indicated in Table 1, the precipitation results in an increase to $\sim 34 \mathrm{MPa}$, i.e. about $20 \mathrm{MPa}$ greater that the base alloy due to the vanadium addition.

The co-precipitation or sequential precipitation of complex nitrides containing primarily titanium and additional vanadium has been reported in the literature frequently, ${ }^{15,16)}$ however the information pertaining to precipitation refinement or increased volume fraction due to combined Ti-V alloying is limited. EPMA (Electron Probe Micro-analysis) study of interdendritic cosegregation of vanadium with nitrogen has shown that vanadium segregation could persist after reheating and hot rolling and promote the formation of a high density of (TiV)N precipitates. ${ }^{16)}$ Siwecki demonstrated that small (TiV)N precipitates enriched with vanadium could form at lower temperatures, whereas coarser (Ti-rich, V)N precipitated at higher temperatures. ${ }^{15)}$ The synergistic effects of various microalloying additions on formation of complex carbonitrides have not been quantified thoroughly and cannot be readily captured by thermodynamic analysis since the interaction parameters between $\mathrm{Ti}, \mathrm{Nb}$ and $\mathrm{V}$ are not well known. ${ }^{17)}$ Small modifications to interaction parameters could shift the system from miscibility to immiscibility of carbonitrides. It has to be noted that the current TEM observations are merely snap shots of the precipitate state at the end of coiling. Although it is not within the scope of the present investigation, studying the evolution of precipitates throughout the different stages of processing, in particular in the as-cast ingot, the reheated condition and following the roughing and finish rolling steps, would be useful to further enhance the understanding of the refinement effect of vanadium addition.

Siwecki et $a l^{5)}$ suggested that the additional strengthening in $\mathrm{V}$ containing bainitic steel could be attributed primarily to the retardation of dislocation recovery effect by $\mathrm{V}(\mathrm{CN})$ precipitates in the dislocation substructure. Precipitation strengthening was also mentioned but only to a lesser extent. The present work confirms that the precipitation strengthening effect due to the carbonitride precipitations in the $\mathrm{V}$-containing X100 steel is partially responsible for the superior strength of the $\mathrm{V}$-added alloy compared with the V-free steel. The strength increment due to vanadium addition was $20 \mathrm{MPa}$ which could not explain the entire observed difference of strength between the two alloys, i.e. $\sim 60 \mathrm{MPa}$. Nevertheless, in V-added steel this large number of small precipitates may prevent dislocation recovery during coiling or interact with mobile dislocations during straining to enhance work hardening. ${ }^{18)}$ In addition, as shown earlier, ${ }^{6}$ the relatively larger fraction of low- 
angle boundaries in $\mathrm{V}$-containing steel indicates possible higher dislocation density in this steel suggesting that the V-containing precipitates might actually have prevented dislocation-recovery, at least to some extent.

The knowledge on the precipitates identified in this work contributes to the understanding of the role of vanadium in strengthening of line pipe steels. However, further work is necessary to isolate the strengthening contribution from each of the possible mechanisms.

\section{Conclusions}

Additional understanding of carbonitride precipitation due to vanadium alloying in a high strength X100 linepipe steel has been obtained from direct TEM observation which sheds light on the underlying strengthening mechanisms in $\mathrm{V}$-containing high strength line pipe steels. The following conclusions can be drawn from the present study:

(1) There is a significantly finer distribution with higher number density of carbonitride precipitates in the $\mathrm{V}$-added sample compared to the base V-free alloy.

(2) Precipitates are more uniformly distributed in the $\mathrm{V}$-added alloy and they are generally of smaller size, i.e. $18 \mathrm{~nm}$ vs. $25 \mathrm{~nm}$. Based on the Ashby-Orowan model, the contribution of precipitates with an average size of $25 \mathrm{~nm}$ to overall strength is $\sim 14 \mathrm{MPa}$ in the base alloy while by considering the average size of $18 \mathrm{~nm}$ for the precipitates in the case of $\mathrm{V}$ addition, the contribution to strength increased to $\sim 34 \mathrm{MPa}$.

(3) The measured volume density of precipitates in alloy A and alloy B were $8.9 \times 10^{12} \mathrm{~cm}^{-3}$ and $9 \times 10^{13} \mathrm{~cm}^{-3}$, respectively - an order of magnitude higher for the $\mathrm{V}$-added alloy

(4) The refinement and increased precipitation of carbonitride particles in $\mathrm{V}$-added alloy are partially responsible for the observed strength difference due to the addition of vanadium.

(5) No evidence confirming the precipitation of vanadium following rolling or during coiling at $450^{\circ} \mathrm{C}$ was found.
(6) Micro alloying with vanadium gave rise to additional $\sim 20 \mathrm{MPa}$ precipitation hardening compared to $\mathrm{V}$-free grade, however this is not sufficient to describe fully the observed strength difference of $\sim 60 \mathrm{MPa}$ between the two variants of X100 steel. It is most likely that other mechanisms are involved; more detailed analyses are underway to determine additional roles of vanadium on microstructure evolution in bainitic linepipe steels.

\section{REFERENCES}

1) American Petroleum Institute: Specification for Line Pipe, API SPECIFICATION 5L, API, USA, (2013).

2) R. Glodowski: Int. Seminar on Application Technologies of Vanadium in Flat Rolled Steels, Vanitec, UK, (2005), 43.

3) A. M. Sage: Met. Technol., 10 (1983), 224.

4) V. Schwinn, P. Fluess and J. Bauer: Rev. Metall. - CIT, 100 (2003), Issue 7, 8, 757.

5) T. Siwecki, J. Eliasson, R. Lagneborg and B. Hutchinson: ISIJ Int., 50 (2010), 760.

6) S. Nafisi, M. Arafin, B. Glodowski, L. Collins and J. Szpunar: ISIJ Int., 54 (2014), 2404.

7) S. Nafisi, M. Arafin, L. Collins and J. Szpunar: Mater. Sci. Eng. A, A531 (2012), 2.

8) D. Q. Bai, S. Yue, W. P. Sun and J. J. Jonas: Metall. Trans. A, 24 (1993), 2151.

9) T. Malis, S. C. Cheng and R. F. Egerton: J. Electron Micros. Tech., 8 (1988), 193

10) R. D. K. Misra, H. Nathani, J. E. Hartmann and F. Siciliano: Mater. Sci. Eng. A, 394 (2005), 339.

11) S. Shanmugam, M. Tanniru, R. D. K. Misra, D. Panda and S. Jansto: Mater. Sci. Technol., 21 (2005), 165.

12) A. J. Craven, K. He, L. A. J. Garvie and T. N. Baker: Acta Mater., 48 (2000), 3857.

13) Y. Oba, S. Koppoju, M. Ohnuma, T. Murakami, H. Hatano, K. Sasakawa, A. Kitahara and J. Suzuki: ISIJ Int., 51 (2011), 1852.

14) T. Gladman: The Physical Metallurgy of Microalloyed Steels, Maney Publishing for The Institute of Materials, London, (1997), 50.

15) T. Siwecki, A. Sandberg and W. Roberts: Processing Characteristics and Properties of Ti-V-N steels, Int. Conf. on Technology and Applications of HSLA Steels, American Society of Metals, OH, (1983), 619.

16) C. Scott, P. Maugis, P. Barges and M. Goune: Proc. Int. Conf. on Advanced High Strength Sheet Steels for Automotive Applications, Association for Iron \& Steel Technology, Warrendale, PA, (2004), 181.

17) M. Prikryl, A. Kroupa, G. C. Weatherly and S. V. Sabramanian: Metall. Mater. Trans. A, 27A (1996), 1149.

18) N. Kamikawa, K. Sato, G. Miyamoto, M. Murayama, N. Sekido, K. Tsuzaki and T. Furuhara: Acta Mater., 83 (2015), 383.

19) P. Duwez and F. Odell: J. Electrochem. Soc., 97 (1950), 299. 